have winter temperatures below this level.5 The government has increased benefit payments to pensioners that defray but do not fully compensate for the addition of VAT to fuel costs. No such help has been provided for families with young children on low incomes, whose numbers below the official poverty line have tripled in the past decade. ${ }^{6}$

The immediate effects on health of this policy are likely to be subtle. Prolonged exposure to cold lowers resistance to infection and adversely affects morale and efficiency. ${ }^{7}$ Inadequately heated buildings often become damp and predispose to respiratory and rheumatic diseases. ${ }^{78}$ Restricted use of rooms may lead to overcrowding. Ample pathophysiological evidence links low temperatures to cardiovascular risk (p 1029)..$^{9}$

A reduction in disposable income resulting from increased fuel charges is also likely to have effects on health. Policies to improve the national diet are already confounded in poor communities, not by ignorance of a healthy diet but by the extra cost and limited availability of healthier foodstuffs. A study of low income families carried out by the National Children's Home found that mothers often had to choose between food or fuel. ${ }^{10}$

Although the thrust of the government's policy of care in the community concerns the balance of care between primary and secondary sectors, the whole edifice crucially depends on maintaining the current balance between primary care and self care. Most affected families are their own "key workers," making best use of limited resources. The government's Energy Efficiency Office states that groups with special needs may require higher ambient temperatures than the general population. ${ }^{11}$ Putting VAT on fuel will reduce disposable income, and make life more difficult, for the army of unpaid carers on whom "care in the community" really depends.

As with many public health issues, the greatest problems arise not with the small numbers of people at high risk but with the large numbers on whom the effects will be small. Thus measures to address individual hardship or extreme weather conditions do not address the problems of large numbers of households with low incomes, above the thresholds for state relief, whose disposable income will be reduced. Like premature death, ${ }^{12}$ this is not a problem that will hit the headlines or be reflected soon in routine data but will be suffered quietly by large numbers of people. Public health advocacy is needed to protect these vulnerable groups.

The current policy of putting VAT on fuel should be opposed on principle because it is unfair and will continue the redistribution of wealth from the poor to the rich within Britain. Although other countries in the European Union impose VAT on fuel, they do not have our housing problem, our pronounced seasonal variation in mortality, or our widening range of income distribution. ${ }^{13}$

The greater public health problem is fuel poverty. No mystery concerns its cause or solution. Improved insulation creates warm, dry homes that cost less to heat, thereby increasing the occupant's disposable income. ${ }^{1}$ These effects should lead in turn to better health, less cost to health and social services, protection of the environment, and increased spending within local economies. In the furore surrounding the government's imposition of VAT on fuel it is important not to lose sight of this broader, more fundamental aspect of public health policy.

GRAHAM C M WATT Professor of general practice

Department of General Practice,

University of Glasgow,

Woodside Health Centre,

Glasgow G20 7LR

1 Sheldrick B. Energy and fuel consumption. In: Fyfe G, ed. Poor and paying for it. Edinburgh: HMSO, 1993:34-53.

2 Boardman B. Fuel poverty: from cold homes to affordable warmth. London: Belhaven Press, 1991.

3 Brooke J. Housing condition survey 1985. Condensation and dampness. Glasgow: Glasgow District Council, 1989:96.

4 Energy Efficiency Office. Degree days. London: EEO, 1987. (Fuel efficiency booklet No 7.)

5 Salvage AV. Cold comfort: a national survey of elderly people in winter. London: Age Concern, 1993.

6 General Statistical Service. Households below average 1994 incomes. London: HMSO, 1994

7 War Office. Manual of army health. London: HMSO, 1959:85-8.

8 Platt SD, Martin CJ, Hunt SM, Lewis CN. Damp housing, mould growth, and symptomatic health state. $B M F$ 1989;298:1673-8.

9 Wilmshurst $P$. Temperature and cardiovascular mortality. BMF 1994;309:1029-30.

10 National Children's Home. Deep in debt. A survey of problems faced by low income families. London: National Children's Home, 1992.

1 Energy Efficiency Office. Guide to home heating costs. London: EEO, 1985.

12 Watt GCM. Differences in life expectancy between Glasgow and Edinburgh: implications for health policy in Scotland. Health Bullerin Edinburgh 1993;51:407-17.

13 Wilkinson RG. Income distribution and life expectancy. BMf 1992;304:165-8.

\title{
A new approach to weighted capitation
}

\section{More sensitive indicators of need but important policy questions remain unanswered}

Equity of access to health care on the basis of need alone is the central principle of the NHS. A corollary of this is that resources should be distributed among local health authorities in proportion to their relative health care needs. But this is difficult in practice because population needs cannot be measured directly and the proxies that are available are difficult to interpret.

Since the publication of the report of the Resource Allocation Working Party in 1976,1 the allocation of resources to hospital and community health services has become progressively more complicated and controversial. ${ }^{23}$ The review of the Resource Allocation Working Party's formula in 1988, which resulted in the introduction of a weighted capitation formula, was widely criticised. 45 Particular concern was expressed about how analyses of variations in hospital use among small areas were used to generate indicators of need.
Prompted by the availability of new data from the census in 1991, the secretary of state for health announced a review of weighted capitation at the beginning of last year. Later this week ministers are expected to publish their conclusions. Although the basis for distributing hospital finances is likely to remain superficially familiar, ${ }^{6}$ substantial changes are expected.

Three articles published in this week's journal explain the bulk of the analytical work that informed the review of weighted capitation. They use much more comprehensive data and more sophisticated statistical methods that are better informed by theory than hitherto. Consequently, they are an important contribution to thinking about needs assessment and allocation of resources.

To begin with Carr-Hill et al describe an approach to a small area analysis of the determinants of hospital use, which was undertaken to identify population based indi- 
cators of the need for health care (p 1046). ${ }^{7}$ Statistical models of small area variations in use of hospital resources were developed in an attempt to distinguish between "legitimate" needs such as health status and deprivation and "illegitimate" influences such as the availability of hospital beds, general practitioners, and nursing homes.

In the second article Smith et al outline the main results of the analyses and show their possible impact at the level of the former regional health authorities (p 1050). ${ }^{8}$ Their four key findings are that the present method of weighted capitation overstates the costs of providing health care to elderly people; socioeconomic characteristics of areas are important determinants of the use of health care in addition to conventional indicators of health status such as mortality; small area indicators of need vary between different services such as acute and psychiatric specialties; and the availability of non-hospital resources has an important bearing on the demand for hospital care. The overall effect of taking these findings into account would be to redistribute resources to relatively deprived inner city areas at the expense of more affluent parts of the country.

The final article, by Sheldon et al, describes an attempt to use routinely collected data about hospital use to identify population based indicators of need that improve the setting of budgets for general practice fundholders (p 1059).9 Despite using the most advanced statistical techniques the authors fail to find any convincing evidence that factors of need other than the age and sex structures of the local population are associated with small area variations in the use of hospital resources. They conclude with some justification that further research is needed to establish a resource allocation formula that is sensitive to variations in the costs of treatment. In the meantime continued vigilance will be required to ensure that incentives for general practitioners to exclude potentially expensive patients are not inadvertently created by any new method of allocating resources to fundholders.

Despite, or even perhaps because of, their complexity the analyses presented in these papers represent a major advance in assessing the relative health care needs of small areas. They respond as far as possible to many of the common criticisms of previous attempts to develop empirically based resource allocation formulas. Nevertheless, some problems remain that are mainly due to inadequacies in the data available for analysis. One deficiency has been the lack of a consistent method of costing episodes of hospital use across specialties. Another is that the indicators used to measure access to health care and the need for treatment are highly correlated with each other, and this hugely complicates the statistical modelling. For example, whether the "illegitimate" influences of supply on observed patterns of hospital use have been, or indeed could ever be, fully taken into account remains debatable.

A wider set of questions exists about the practical interpretation of the findings that relate to the narrow terms of reference within which the analysts had to work rather than the quality of their work itself. For example, although the review of weighted capitation was confined to the hospital and community health services, one may clearly infer from the papers that it is a serious mistake to evaluate relative needs for hospital services in isolation of an assessment of similar requirements for primary and community based care. A more comprehensive approach to establishing the relative health and social needs of different areas that transcends arbitrary service and administrative boundaries is now required. The latest research reported in this week's journal highlights the illogicality of, for example, allocating money to purchasers in London to buy hospital services without taking account of the relative lack of facilities for continuing care in the capital.

KEN JUDGE Director

NICHOLAS MAYS

King's Fund Institute,

London W2 4HT

1 Department of Health and Social Security. Sharing resources for health in England: report of the Resource Allocation Working Party. London: HMSO, 1976.

2 Royston GDH, Hurst JW, Lister EG, Stewart PA. Modelling the use of health services by populations of small areas to inform the allocation of central resources to larger regions. Socio-Econ Planning Sci 1992;26:169-80.

3 Carstairs V. Health care needs, deprivation, and the resource allocation formula. In: Gilman E, et al, eds. Resource allocation and health needs: from research to policy. London: HMSO, 1994: 5-18.

4 Mays N. NHS resource allocation after the 1989 white paper: a critique of the research for the RAWP review. Community Medicine 1989;11:173-86.

Sheldon TA, Davey Smith G, Bevan G. Weighting in the dark: resource allocation in the new NHS. BMY 1993;306:835-9.

6 Judge K, Mays N. Allocating resources for health and social care in England. BMF ; 308:1363-6.

7 Carr-Hill RA, Sheldon TA, Smith P, Martin S, Peacock S, Hardman G. Allocating resources to health authorities: development of method for small area analysis of use of inpatient services. BMF 1994;309:1046-9.

8 Smith P, Sheldon TA, Carr-Hill RA, Martin S, Peacock S, Hardman G. Allocating resources to health authorities: results and policy implications of small area analysis of use of inpatient services. $B M F$ 1994;309:1050-4.

9 Sheldon TA, Smith P, Borwitz M, Martin S, Carr-Hill R. Attempt at deriving a formula for setting general practitioner fundholding budgets. BMf 1994;309:1059-64.

\section{The future of purchasing}

\section{Tolerance of diversity will be necessary}

At last week's Conservative party conference the government's plans for the future of fundholding were unveiled. ${ }^{1}$ To understand the significance of these it is important to remember the history of purchasing so far. Working for Patients established two models of purchasing, one centred on health authorities and the other on general practitioners. Health authorities approach purchasing from a population perspective and bring to bear a range of skills in public health and other disciplines to assess health care needs. On the basis of needs assessment, health authorities buy the full range of care for their population except for those services under the control of fundholders. Fundholders are responsible for purchasing a limited list of services and do so in a way that is responsive to patients' demands. There is therefore a contrast between needs based purchasing by health authorities and demand led purchasing by fundholders.

In practice, health authorities and general practitioners in different parts of the NHS have developed a range of approaches to purchasing, which seek to combine the leverage of health authorities with the bite of fundholders. ${ }^{2}$ These include general practitioners giving advice to health authorities, locality purchasing, practice sensitive purchasing, fundholding consortiums, general practitioner multifunds, and total fundholding. All these initiatives have emerged spontaneously as policy has been driven from the bottom up rather than the top down. One of the consequences has been competition among purchasers as those involved in different approaches seek to show that they are best placed to achieve improved services. 